vị trí. Ngày nay, chọc hút kim nhỏ dưới hướng dẫn của siêu âm đã được thực hiện phổ biến ở nhiều nước trên thế giới và được xem là một phương pháp tốt nhất để đánh giá bản chất của nhân giáp. Tuy nhiên, độ chính xác của phương pháp còn phụ thuộc rất nhiều kỹ thuật thực hiện, kinh nghiệm đọc tế bào...

Trong nghiển cứu này, khi thực hiện kỹ thuật chúng tôi không gặp bất cứ trường hợp nào xảy ra tai biến và biến chứng trong và sau khi chọc. Vì vậy có thể kết luận phương pháp tế bào học chọc hút kim nhỏ dưới hướng dần của siêu âm là kỹ thuật an toàn, tỷ lệ chọc trúng tổn thương cao, nhất là với các bướu nhân nhỏ $<1 \mathrm{~cm}$, nằm sâu không sờ thấy được trên lâm sàng, có thể triển khai rộng rãi ở nhiều cơ sở y tế.

\section{KẾT LUẬN}

- Nhóm tuổi có tỷ lệ mắc bệnh cao nhất là 50

- 59 (29,6\%), nhóm tuổi < 30 chiếm tỷ lệ thấp.

- Bệnh nhân nữ chiếm đa số $(89,2 \%)$, tỷ lệ nũ̃/nam $=8,3 / 1$.

- Kết quả chẩn đoán tế bào học: bướu nhân lành tính $(95,4 \%)$, ung thư biểu mô tuyến giáp thể nhú $3,4 \%$, nghi ngờ $(1,2 \%)$.

- Kết quả chẩn đoán mô bệnh học: bướu giáp keo lành chiếm tỷ lệ $70,9 \%$, UTBM thể nhú $19,4 \%$, u tuyến nang $9,7 \%$.

- Giá trị chẩn đoán tế bào học chọc dưới hướng dẫn của siêu âm:

Độ nhạy: $6 / 6=100 \%$

Độ đặc hiệu: $23 / 25=92 \%$

Độ chính xác: $29 / 31=93,5 \%$
Giá trị chẩn đoán dương tính: $6 / 8=75 \%$

Giá trị chẩn đoán âm tính: $23 / 23=100 \%$

TÀl LIỆU THAM KHẢO

1. Nguyễn Khoa Diệu Vân (2013), "Nội tiết học trong thực hành lâm sàng", NXB Y hoc, trang 110118.

2. Chu Thị Giang (2018), Nghiên cứu đặc điểm lâm sàng, cận lâm sàng và kết quả chọc hút bướu nhân tuyến giáp tại Bệnh viện đa khoa tỉnh Ninh Bình, Luận văn tốt nghiệp bác sỹ chuyên khoa II, Đai học Y Dược Thái Bình.

3. Trẫn Mạnh ìa (2013), " Nhận xét kết quả giải phẫu bệnh và hình ảnh siêu âm trong chẩn đoán bệnh lý tuyến giáp tại bệnh viện đa khoa tỉnh Thái Bình", Y học thực hành sô 887+888, 46-49.

4. Nguyễn Thị Hoa Hông (2012), Nghiên cứu đặc điểm lâm sàng, siêu âm, choc tế bào kim nhỏ và sinh thiết tức thì trong chẩn đoán bướu nhân tuyến giáp, Luận văn tốt nghiệp bác sỹ nội trú, Đại học Y Hà Nội.

5. Trû̀n Văn Tuấn, Nguyễn Đình Tùng (2010), "Khảo sát hình ảnh siêu âm và chọc hút tế bào kim nhỏ dưới hướng dẫn siêu âm các khối bất thường tuyến giáp tai Bệnh viện trung ương Huế", Tạp chí Y Học TP. Hồ Chí Minh * Tập 14 * Phụ bản của Số $4 * 2010$.

6. Pinchot SN, Al-Wagih H, Schaefer S (2009), "Accuracy of fine-needle aspiration biopsy for predicting neoplasm or carcinoma in thyroid nodule", Arch Surg, 144:649-655.

7. Lê Hồng Cúc (2002), "Phát hiện sớm ung thư tuyến giạp bằng siêu âm kết hợp với chọc hút tế bào bằng kim nhỏ", Kỷ yếu toàn văn hội nghị chẩn đoán hình ảnh và y học hạt nhân thành phố Hồ Chí Minh mở rộng. Tháng 3 - 2002.

8. Douglas S (2002). Non - palpable Thyroid Nodules - Managing an Epidemic, The Journal of Clinical Endocrinology Metabolisme, 87(5), 1983 - 1990

\title{
KẾT QUẢ NộI SOI KHỚP GỐI CỐ ĐINHH BONG ĐIỂM BÁM DÂY CHẰNG CHÉO TRƯớC
}

\author{
Nguyễn Ngọc Sinh ${ }^{1}$, Nguyễn Vũ Hoàng ${ }^{1}$, \\ Hoàng Văn Dung' ${ }^{2}$ Vũ Mạnh Cường ${ }^{2}$, Nguyễn Thế $\mathrm{Anh}^{2}$
}

\section{TÓM TẮT}

Đă̆t vấn đề: Bong điểm bám chày dây chằng chéo trước (DCCT) được phân loại theo Meyer và McKeever là một chấn thương bong nhiều mảnh di lệch nơi bám chày của DCCT khớp gối. Có nhiều cách điêu trị qua mổ mở hoặc nội soi như: bằng vít, đinh, chỉ thép hoặc

\footnotetext{
${ }^{1}$ Trường Đại học Y dược Thái Nguyên ²Bênh viện TW thái nguyên

Chịu trách nhiệm chính: Nguyễn Ngọc Sinh

Email: nguyenngocsinh0205@gmail.com

Ngày nhận bài: 20.8.2021

Ngày phản biện khoa học: 18.10.2021

Ngày duyệt bài: 18.10.2021
}

khâu cố định. Khâu néo ép cố định dưới nội soi là kỹ thuật tiến bộ mới ít xâm nhập vẫn còn nhiều thách thức trong nghiên cứu của các phẫu thuật viên hiện nay. Mục tiều nghiên cứu: Đánh giá kết quả phục hồi về lẩm sàng và $X$ quang sau khâu qua nội soi điểu trị bong nơi bám chày DCCT bằng chỉ siêu bền. Đối tượng và Phương pháp nghiên cứu: Từ ngày 01 tháng 01 năm 2015 đến ngày 30 tháng 06 năm 2021, có 33 trường hợp bong nơi bám chày DCCT được điêu trị bằng kỹ thuật khâu dưới nội soi với chỉ siểu bền. Phương pháp nghiên cứu là nghiên cứu mô tả. Đánh giá kết quả dựa vào: đánh giá tầm vận động khớp, dấu Lachmann và điểm số Lysholm, Noyes, kết quả Xquang sau mổ. Kết quả: 33 bệnh nhân tuổi TB 30, được theo dõi trung bình 14 tháng. Điểm số trung 
bình sau mổ Lysholm là 95, IKDC là 27 ca loại $A$, còn lại loại $B$, sau mổ test Lachmann thây vững gối tốt là 31 ca $(93,9 \%)$. Tất cả trường hợp hồi phục hoàn toàn tầm độ khớp. Thương tổn trong gối đi kèm $11 \mathrm{ca}$ không ảnh hưởng nhiều đến kết quả phục hồi. Tất cả đều đi làm lại như trước mổ. Không ghi nhận có trường hợp nào bi nhiễm trùng sau mổ. Khâu lại nơi bám dây chằng bắng chỉ siêu bền đủ vững cho phép tập vận động sớm khớp gối lợi hơn kết hợp xương bên trong bằng vít xốp phải mố lấy ra lần thứ hai. Kết luân: Nôi soi cố đinh lại chỗ bong điểm bám chày DCCT kỹ thuật khâu néo qua nội soi là phương pháp an toàn và hợp lý. Khâu cố định mảnh gãy vững chắc, đúng vị trí giải phẫu bằng chỉ siêu bền giúp lành dây chằng tốt

Tư khóa: Bong nơi bám dây chằng chéo trước (DCCT), Nội soi khớp.

\section{SUMMARY \\ RESULTS ARTHROSCOPIC KNEE FIXATION OF DISPLACED COMMUNITED ANTERIOR CRUCIATE LIGAMENT (ACL) AVULSION FRACTURES \\ Background: The Anterior cruciate ligament} (ACL) avulsion which was classified by Meyers and McKeever was displaced comminuted fractures. Now, arthroscopic reduction, surgical repair is emerging as the state-of-the-art challenge of treatment. Objectives: The aim of our study was to assess the clinical and radiological results of arthroscopic Suture fixation with PDS IIin the management of ACL avulsion fractures. Materials and Methods of study: From 01 Jan 2015 to 30 June 2021, 33 cases of ACL tipial avulsions i were treated with Arthroscopic reduction, internal fixationusing nonabsorbable sutures passed through drill holes and tied together in the tibial tubercle is now preferred. Method of study is desciptive prospective. All patients were assessed clinically by calculating their Lysholm, Noyes scores and Lachmann test, ROM of knee, and the radiological union was assessed in the followup radiographs. Results: There are 33 patients. The mean age was 30 years with a mean followup of 14 months. The mean Lysholm score was 95 and IKDC 27 case type $A$ and all other case B. In $31(93,9 \%)$ patients Lachman test was negative at the end of final. ROM of knee in 33 cases is normal. Associated knee injuries were found in 11 cases. The final outcome was not greatly influenced by the presence of associated injuries when treated simultaneously. At final followup all the patients were able to return to their pre- injury occupation.. The radiological union was observed in all cases. No case was infectious in post-opperation. Repair using nonabsorbable suture fixation, when of adequate strength to allow early range-of-motion, has the advantages of eliminating the risks of comminution of the fracture fragment, posterior neurovascular injury, and without hardware removal, compared with internal fixation using screws. Conclusion: Arthroscopic suture fixation is a safe and reliable method for producing clinical and radiological outcome in displaced communited $\mathrm{ACL}$ avulsion fractures. Arthroscopic anatomic reduction, internal fixationusing PDS II nonabsorbable sutures passed through drill holes and tied together in the tibial tubercle is favor for healing ligament.

Key words: Anterior cruciate ligament (ACL) avulsion, arthroscopy.

\section{I. ĐẶT VẤN ĐỀ}

Gãy bong điểm bám chày dây chằng chéo trước (DCCT) là một trong những tổn thương thường gặp của chấn thương vùng gối và là 1 trong 3 dạng đứt của DCCT gôm có: DCCT có thể bi bong khỏi nguyên ủy của lồi câu đùi, có thể bị đứt ở phân thân hoặc bị nhổ khỏi điểm bám tận ở mâm chày[2][5]. Tổn thương này nếu không được điều trị gây lỏng khớp gối ra trước làm mất vững gối trong lao động và hoạt động thể thao[5].

Tổn thương này theo Meyer, Keevers và Zaricznyj được chia làm 4 độ, trong đó độ I thường có thể điều trị bảo tôn; độ II, III gãy di lệch nhiều và độ IV gãy bong nhiêuu mảnh nhỏ di lệch nhiều là loại có chỉ định phẫu thuật [6][9].

Tai Bênh viện TƯ Thái Nguyên, phấu thuât nội soi khớp gối điêu trị bong điểm bám chày DCCT đã thực hiện từ năm 2014 và trở thành phẫu thuật thường quy. Kỹ thuật này được triển khai đã đáp ứng được nhu câu điêuu tri, không chỉ cho người bệnh trên địa bàn tỉnh Thái Nguyên mà còn cho bệnh nhân các tỉnh lân cận... Tuy nhiên chưa có nghiên cứu nào đánh giá kết quả phẫu thuâtt, cũng như tìm hiểu về các yếu tố ảnh hưởng đến kết quả phẫu thuật, nhằm rút ra bài học kinh nghiệm để thực hiện tốt hơn, hoàn thiện hơn về chỉ định, kỹ thuật nội soi khớp gối điều trị bong điểm bám chày DCCT khớp gối cho các ca bệnh tiếp theo. Mục tiêu nghiên cứu

Đánh giá kết quả phục hồi về lâm sàng và $X$ quang sau phẫu thuật nội soi khớp điều trị bong điểm bám chày DCCT bằng chi siêu bền.

\section{II. ĐỐI TƯỢNG VÀ PHƯƠNG PHÁP NGHIÊN CỨU}

2.1 Đối tượng nghiên cứu. Gồm các bệnh nhân được nội soi cố định bong điểm bám chày dây chằng chéo trước khớp gối tại khoa Chấn thương chỉnh hình Bệnh viện TƯ Thái Nguyên từ tháng 01/2015 đến 06/2021

Tiêu chuân lựa chọn. Gồm tất cả bệnh nhân bị bong điểm bám DCCT khớp gối độ IIIV[9], có đây đủ bệnh án, chụp phim Xquang trước và sau mổ, bệnh nhân đồng ý tham gia nghiên cứu[7].

Tiêu chuẩn loai trừ. Bệnh nhân có các bệnh lý trước đây gây hạn chế vận động một hoặc hai chi dưới: cứng gối, thoái hóa gối nặng... Bệnh nhân tổn thương đồng thời khớp đối diện, gây 
hạn chế vận động cùng thời gia điều trị bing điểm bám DCCT bên nghiên cứu, bệnh nhân có gãy xương chi dưới kèm theo: gãy xương đùi, xương cẳng chân...

\section{Phương pháp nghiên cứu}

2.1. Phương pháp nghiên cứu mô tả. Thiết kế nghiên cứu cắt ngang

2.2 Cõ̃ mẫu nghiên cứu. Cõ̃ mẫu toàn bộ bệnh nhân đã phẩu thuật cố định bong điểm bám DCCT khớp gối theo đúng tiêu chuẩn lựa chọn.

Chọn mẫu chủ đích, gồm 33 bệnh nhẩn

Phương pháp phấu thuật. Bệnh nhân được tê tủy sống, nằm ngửa trên bàn mổ, ga-rô đừi, gối gấp tự do khoảng $90^{\circ}$.

Nội soi vào khớp qua 2 vị trí cạnh gân bánh chè, dùng lưỡi bào khớp và lưỡi bào công nghệ Radio dọn trong khớp gối để quan sát rõ hơn:

- DCCT bị bong vị trí điểm bám tại mâm chày, di lệch khỏi vị trí cũ nhiều không bị đứt, rách tại thân. Quan sát sụn chêm nếu tổn thương thì cắt sửa tạo hình hay khâu.

- Chúng tôi áp dụng phương pháp khâu qua phía trên mảnh gãy bằng chỉ siêu bền, sau đó luồn xuống dưới tạo hình số 8.

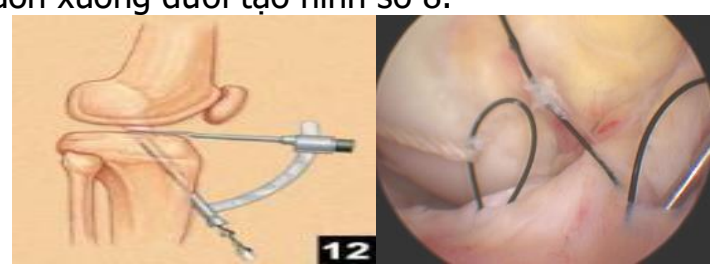

Hình 1: Hình vẽ khoan đường hầm và khâu dây chằng qua nội soi

Nắn lại ổ gãy bằng móc, đặt dụng cụ định vị lên mảnh̆ gãy với góc khoan 55 độ, sử dụng khoan dẫn đường đk $2 \mathrm{~mm}$ khoan đường hầm thứ nhất ở cạnh bờ trong gốc DCCT. Tương tự khoan tạo đường hầm thứ 2 ở cạnh bờ ngoài gốc DCCT.

Từ lỗ vào phía trong gối dùng dụng cụ luồn chỉ chờ qua gốc dây chằng (tương ứng với vị trí $2 / 3$ trước và $1 / 3$ sau của đường kính gốc $D C C T$ ).

Qua 2 đường hầm luồn kéo chỉ siêu bền xuống sao cho 2 sợi chỉ bắt chéo trên mảnh gãy tạo hình số 8 , giữ chắc điểm bám DCCT bị bong, duỗi gối và buộc 2 đầu chỉ lại với nhau, DCCT căng giãn tối đa để vững khớp gối sau này.

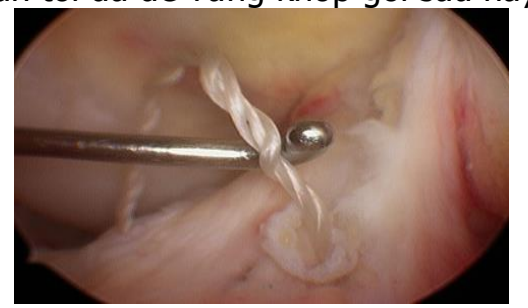

Hình 2: Khâu luồn qua đường hầm song song
Bơm rửa sạch khớp gối, kiểm tra lại DCCT căng chắc, xả ga- rô, khâu vết mổ, đặt dẫn lưu khớp gối. Sau mổ kiểm tra lại Lachmann test (-).

Chăm sóc và tập phục hồi chức năng sau mổ

Sau mổ bệnh nhân được đeo nẹp gối thẳng để bất động khớp gối, dẫn lưu rút sau 48 giờ. Ngay hôm sau khi phẩu thuật, bệnh nhân được hướng dẫn tập gồng trong nẹp cơ tứ đầu đưii, gập duỗi cổ chân, chườm lạnh gối phẫu thuật.

Mang nẹp gối 3 tuần, lúc đó bệnh nhân bớt đau, gối bớt sưng. Lúc này bắt đầu gấp duỗi gối tích cực, đi nạng chịu sức nặng tăng dần. Sau 2 tháng, khớp gối gấp duỗi hoàn toàn, bắt đâu tập cơ tứ đầu đùi bằng cách nâng tạ, tập xe đạp... sau 6 tháng có thể chơi thể thao, làm việc nặng trở lai.

\section{KẾT QUẢ NGHIÊN CỨU}

Từ ngày 01 tháng 01 năm 2015 đến ngày 30 tháng 06 năm 2021, có 33 trường hợp bong nơi bám chày DCCT được điều trị bằng kỹ thuật nội soi cố định điểm bám với chỉ siêu bền (thực hiện tại khoa Chấn thương chỉnh hình Bệnh viện Trung ương Thái Nguyên). Thời gian theo dõi trung bình từ 1- 24 tháng có kết quả như sau:

\section{Kết quả điêu trị:}

1. Tuổi: Trung bình $30,58 \pm 11,26$ tuổi (từ 10- 55 tuổi)

2. Giới: Nam 16 (48,5\%) Nữ: $17(51,5 \%)$.

3. Gối chấn thương: Gối trái $(48,5 \%)$ Gối phải $(51,5 \%)$

Trước chấn thương các bệnh nhân đều có tình trạng vận động khớp gối bình thường, lao động, chơi thể thao. Không điều trị bệnh lý khớp gối bên phẫu thuật.

4. Nguyên nhân chấn thương: Tai nạn gioa thông $26(78,8 \%)$, tai nạn sinh hoạt, lao động $4(12,1 \%)$, tai nạn thể thao $3(9,1 \%)$.

\section{Kết quả sau phẫu thuâat:}

5.1. Kết quả gần (sau phẫu thuật - 3 tháng gồm $33 \mathrm{BN}$ ):

- Điểm Lysholm sau phẫu thuật: Rất tốt (91100 điểm) có 8 BN $(24,2 \%)$, tốt (84-90 điểm) 23 BN $(69,7 \%)$, trung bình (65-83 điểm) 2 BN $(6,1 \%)$, kém (<65 điểm) không có bệnh nhân nào.

- Độ vững chắc khớp gối sau phẫu thuật theo IKDC: Độ A 19 BN $(57,6 \%)$, độ B 14 BN $(42,4 \%)$, độ $C, D$ không có $B N$ nào.

5.2. Kết quả xa (sau phẫu thuật $>6$ tháng gồm $29 \mathrm{BN}$ ):

- Điểm Lysholm sau PT trên 6 tháng:

\begin{tabular}{|c|c|c|}
\hline Thang điểm Lysholm & $\begin{array}{c}\text { Số beểnh } \\
\text { nhẩn }\end{array}$ & $\begin{array}{c}\text { Tỉ lệ } \\
\text { (\%) }\end{array}$ \\
\hline Rất tốt (91-100 điếm) & 19 & 57,6 \\
\hline
\end{tabular}




\begin{tabular}{|c|c|c|}
\hline Tốt (84- 90 điếm) & 10 & 30,3 \\
\hline \hline Trung bình (65- 83 điếm) & 0 & 0 \\
\hline Kém (<65 điếm) & 0 & 0 \\
\hline Tống số & 29 & 87,9 \\
\hline
\end{tabular}

- Đô̂ vững chắc khớp gối sau phầu thuât theo IKDC: Độ A 27 BN (81,8\%), độ B 14 (42,4\%), độ C,D không có bênh nhân nào

- Thời gian BN chơi lại thể thao, hoạt động gắng sức:

\begin{tabular}{|c|c|c|}
\hline Thời gian & Số bệnh nhân & Tỉ lệ (\%) \\
\hline 5-6 tháng & 13 & 24,2 \\
\hline 7-8 tháng & 11 & 51,5 \\
\hline$\geq 9$ tháng & 5 & 12,1 \\
\hline Tống số & 29 & 87,9 \\
\hline
\end{tabular}

6. Biến chứng: Không có nhiếm trùng vết mổ sau khi khám lại, không có trường hợp nào cân can thiệp mổ lại, không có trường hợp nào tiêu điểm bám DCCT

\section{BÀN LUÂN}

1. Đặc điểm của nhóm nghiên cứu: Trong nhóm nghiên cứu gồm 33 bệnh nhân bong điểm bám DCCT khớp gối được điều trị phẫu thuật nội soi cố định bằng chỉ siêu bền tại khoa Chấn thương chỉnh hình bệnh viện Trung ương Thái Nguyên chúng tôi thấy rằng: tuổi trung bình của các bệnh nhân bong điểm bám DCCT khớp gối là 30,58 tuổi trong đó lứa tuổi 20-29 là chiếm nhiêu nhất 48,5\% là lứa tuổi trẻ, xương chắc tuy nhiên do chấn thương mạnh, trực tiếp dẫn đến bong nhổ điểm bám DCCT, nhóm trên 50 tuổi chiếm 12,1\% là lứa tuổi xương chất lượng không còn tốt, nên dễ bong, gãy điểm bám. Nguyên nhân chủ yếu là do tai nạn giao thông chiếm $78,8 \%$, tai nạn sinh hoạt là $12,1 \%$, tai nạn thể thao chiếm $9,1 \%$. Chúng tôi thây rằng nguyên nhân tai nạn giao thông vẫn chiếm tỉ lệ lớn nhất, phù hợp với các nghiên cứu của Quàng Văn Hải (2013) là 66,7\% [3], của Bùi Anh Tuấn (2018) là $85,7 \%$.[1]

2. Tình trạng vận động khớp gối của bệnh nhân: Đia số các bệnh nhân sau phẫu thuật đều giảm mức độ đau, gân như không đau. Các bệnh nhân đạt được điểm lysholm trung bình 94,5 điểm, điểm IKDC đạt độ $A$ là $81,8 \%$. Bệnh nhân được theo dõi trong thời gian trung bình 14 tháng đều không có trường hợp nào nhiễm trùng khớp gối, mức độ can xương theo Lieberman độ 5 là 25 trường hợp, độ 4 là 4 trường hợp, mức độ can xương rất tốt, vững chắc.

3. Liền quan phân độ gãy theo Meyer và McKeever và kết quả chung. Kết quả của chúng tôi cho thấy các trường hợp độ IV đều đạt kết quả chung tốt, độ II, III có 2 trường hợp đạt kết quả trung bình còn lại đều tốt. Có thể thây được việc nắn chỉnh lại mảnh gãy đúng vị trí là khó nhưng với phương pháp cố định điểm bám DCCT bằng chỉ siêu bền thì kết quả rất tốt, kể cả độ IV cũng đạt được kết quả tốt.

Khi áp dụng kỹ thuật khâu néo bằng chỉ siêu bền sưới nội soi chúng tôi nhận ra một số ưu điểm và khuyết điểm của phương pháp này như sau:

Uu điểm: Có thể thực hiện được với cả độ IV, đạt kết quả tốt.

Nội soi thây tổn thương rõ hơn, ít làm tổn thương bao khớp, seo thẩm mỹ

Khâu cố định bẳng chỉ siêu bền vững chắc, không phải phẫu thuật lại thì hai.

Phục hôi chức năng khớp gối sau mổ tốt hơn, áp dụng điều trị cho mọi lứa tuổi từ thanh thiếu niên đến người già.

Khuyêt điểm: Cân có hệ thống máy nội soi hoàn chỉnh

Phẫu thuật viên phải được huấn luyện về nội soi khớp gối

Kỹ thuật thực hiện phức tạp hơn so với mổ mở bắt vít

\section{KẾT LUẬN}

Đối với các trường hợp gãy bong điểm bám chày DCCT khớp gối được phẫu thuật nội soi cố định lại điểm bám bằng chỉ siêu bền cho kết quả tốt, là phương pháp ưu điểm mục đích phục hồi giải phẫu, phục hồi chức năng khớp gối, thực hiện sớm không phải tái tạo lại DCCT.

Trong nghiên cứu của chúng tôi nhận thây phẫu thuật nội soi cố định điểm bám chày DCCT kết hợp phục hồi chức năng sau mổ giúp bệnh nhân giảm đau, sớm trở lại sinh hoạt bình thường

\section{TÀI LIÊU THAM KHẢO}

1. Bùi Tuấn Anh (2018), Đánh giá kết quả điều trị bong điểm bám dây chăng chéo trước khớp gối bằng phẩu thuâtt nội soi ở Bênh viện Xanh Pôn, Luận văn chuyên khoa cấp II, Trường Đại học Y Hà Nội.

2. H.Netter, Frank (2012), Ảtlas giải phẩu người, lần 5 , Nhà xuất bản Y hoc, Hà Nôi.

3. Quàng Văn Hải (2013), Đánh giá kết quả điều tri bong điểm bám dây chằng chéo trước khớp gối bẳng phẫu thuật nội soi tại Bệnh viện Việt Đức, Luận văn thac sĩ y học, Học viên Quân y.

4. Lề Hanh (2005), Đánh giá kết quả điêu trị bong điểm bám dây chẳng chéo trước khớp gối bắng kỹ thuât nôi soi, Luân văn thac sĩ y học, Hoc viên Quân y.

5. Nguyến Xuân Thùy (2013), Phẫu thuật nội soi khớp gối, Nhà xuất bản Y hoc, Hà Nội.

6. Zaricznyj B (1977), "Avulsion fracture of the tibial eminence: treatment by open reduction and pinning", J Bone Joint Surg Am. 59(8), pp. 1111-4.

7. Gans, I., Babatunde, O. M., and Ganley, T. J. (2013), "Hybrid fixation of tibial eminence fractures in skeletally immature patients", Arthrosc Tech. 2(3), pp. e237-42. 
8. Kobayashi, S., et al. (2018), "Arthroscopic Treatment of Tibial Eminence Avulsion Fracture With Suture Tensioning Technique", Arthrosc Tech. 7(3), pp. e251-e256.
9. Meyers, M. H. and Mc, Keever Fm (1959), "Fracture of the intercondylar eminence of the tibia", J Bone Joint Surg Am. 41-a(2), pp. 209-20; discussion 220-2.

\section{MộT Số YẾU TỐ ẢNH HƯởNG TỚI HOẠT ĐộNG NGHIÊN CỨU KHOA HỌC TẠI VIÊ̂N HUYÊT HỌC - TRUYỀN MÁU TRUNG ƯƠNG}

\section{TÓM TẮT.}

Mục tiêu: Mô tả một sỗ yễu tố ảnh hưởng tới hoạt động nighiên cứu khoa học tại Viện Huyết học - Truyền máu Trung ương giai đoạn 2016-2020. Đối tượng và phương pháp: Nghiên cứu từ tháng 4-10/2021 với thiết kế mô tả cắt ngang, kết hợp định lượng và định tính. Đối tượng gồm 26 cán bộ nhân viên tham gia phỏng vấn và 425 đề tài, 280 bài báo khoa hoc của Viênn từ 2016-2020. Kêt quả: Có 425 đề tài được thực hiện tại Viện, có sự khác biệt về hoạt động NCKH giữa các khối, các trình độ học vấn và chuyên ngành đào tao. Khối lâm sàng có số đề tài, bài báo và tỳ lệ nhân viên tham gia NCKH cao nhất. Tỷ lệ chủ nhiệm đề tài và tác giả bài báo cao nhất ở đối tương bác sĩ $(31 \%$ và $31,6 \%)$, thấp nhất ở đối tượng điều dướng $(7,8 \%$ và $3,2 \%)$. Quan điểm, chiến lược, chính sách khuyến khích và kinh phí hỗ trợ $\mathrm{NCKH}$ của viện, vai trò của lãnh đao khoa phòng, trình độ học vấn cao là các yếu tố cơ bản thúc đẩy NCKH tại viện. Kết luận: Quản lý, điều hành, tài chính và nhân lực là các yếu tố ảnh hưởng tới hoat động NCKH tại Viện.

Từ khoá: Hoạt động NCKH, yếu tố ảnh hưởng, Viện Huyết học - Truyền máu Trung ương.

\section{SUMMARY}

\section{SOME FACTORS AFFECTING SCIENTIFIC} RESEARCH ACTIVITIES AT THE NATIONAL INSTITUTE OF HEMATOLOGY AND BLOOD TRANSFUSION

Objective: Describe some factors affecting scientific research activities at the National Institute of Hematology and Blood Transfusion (NIHBT) for the period 2016-2020. Subjects and methods: Applying cross-sectional design, combining quantitative and qualitative. This study implemented from April to October 2021. The subjects included 26 staff members who participated in interviews and 425 topics and 280 scientific articles of the NIHBT from 2016-2020. Results: There are 425 projects carried out at the NIHBT, there are differences in scientific research

*Viện Huyết học - Truyền máu Trung ương

**Trướng Đai hoc Y tế công công

Chịu trách nhiệm chính: Ngô Huy Minh

Email: huyminh162@gmail.com

Ngày nhận bài: 3.9.2021

Ngày phản biên khoa hoc: 26.10.2021

Ngày duyệt bài: 5.11.2021
Ngô Huy Minh*, Bạch Quốc Khánh*, Nguyễn Hà Thanh*, Vũ Thị Hoàng Lan**

activities between blocks, educational levels and training majors. The clinical division has the highest number of topics, articles and the percentage of staff participating in scientific research. The percentage of topic leaders and article authors was highest among doctors (31\% and $31.6 \%$ ), the lowest among nurses $(7.8 \%$ and $3.2 \%)$. The NIHBT's viewpoints, strategies, policies to encourage and support scientific research, the role of faculty leaders, and high educational attainment are the basic factors promoting scientific research at the NIHBT. Conclusion: Management, administration, finance and human resources are factors affecting scientific research activities at the NIHBT.

Keywords: Scientific research activities, National Institute of Hematology - Blood Transfusion.

\section{I. ĐẶT VẤN ĐỀ}

Nghiên cứu khoa học (NCKH) luôn được coi là hoạt động mang tính then chốt và là một trong bảy nhiệm vụ chính của các bệnh viện. Hàng năm, Viện Huyết học - Truyền máu Trung ương có khoảng 60 đề tài NCKH các cấp về chuyên môn và quản lý được phê duyệt, nghiệm thu và áp dụng thực tế. Tuy nhiên, có sự khác biêt về tỷ lệ tham gia NCKH giữa các khối, khoa phòng và đối tượng. Do đó, chúng tôi thực hiện đề tài với mục tiêu: Mô tả môt số yếu tố ảnh hưởng hoạt động nghiên cứu khoa học tại Viện Huyết họ Truyền máu Trung ương giai đoạn 2016-2020.

II. ĐỐI TƯỢNG VÀ PHƯƠNG PHÁP NGHIÊN CỨU

\section{1. Đối tượng nghiên cứu:}

- Đinh tính: 26 người bao gồm đại diên lãnh đạo Viện, các khoa phòng liên quan, viên chức của Viện.

- Định lượng: 425 đề tài, 280 bài báo của Viện giai đoạn 2016-2020.

2.2. Thiết kế nghiên cứu: Mô tả cắt ngang kết hợp định lượng và định tính.

2.3. Phương pháp chọn mẫu và cỡ mẫu: Chon chủ đích 26 đối tượng nghiên cứu định tính: Lãnh đạo viện, bác sĩ, điêu dưỡng, kỹ thuật viên và đối tượng ngoài ngành $y$, chủ nhiệm đề tài, tác giả bài báo, đối tượng không tham gia $\mathrm{NCKH}$....và các đề tài, bài báo liên quan. 